\title{
Medication Errors among Physician-Assistants Anaesthesia
}

\author{
G. Amponsah, ${ }^{1}$ A. Antwi-Kusi, ${ }^{2}$ W. Addison, ${ }^{2}$ and B. Abaidoo ${ }^{3}$ \\ ${ }^{1}$ Department of Anaesthesia and Pain Management, University of Cape Coast, School of Medical Sciences, Cape Coast, Ghana \\ ${ }^{2}$ Department of Anaesthesia and Intensive Care, Kwame Nkrumah University of Science and Technology, \\ School of Medical Sciences, Kumasi, Ghana \\ ${ }^{3}$ Department of Surgery, Eye Unit, University of Ghana Medical School, Korle-Bu Teaching Hospital, Accra, Ghana
}

Correspondence should be addressed to G. Amponsah; gamponsah2006@yahoo.com

Received 16 December 2015; Revised 23 February 2016; Accepted 6 March 2016

Academic Editor: Jukka Kortelainen

Copyright ( $\odot 2016$ G. Amponsah et al. This is an open access article distributed under the Creative Commons Attribution License, which permits unrestricted use, distribution, and reproduction in any medium, provided the original work is properly cited.

Background. Safety issues in anaesthesia are currently being discussed widely. Anaesthetists have a unique cross-specialty opportunity to influence the safety and quality of patient care. Anaesthetists administer very potent drugs, in rapid succession, during the course of one anaesthesia event. Methodology. The study was done in April 2013 at the annual refresher course of the Physician-Assistants Anaesthesia using a questionnaire which was completed by the participants on the course. The data was analysed using IBM SPSS Statistics software version 20. Results. There were 164 completed questionnaires, with 92 (62.2\%) males and $56(37.8 \%)$ females with a mean age of 32.3 years. The majority of them $(66.5 \%)$ work in government hospitals. One hundred and seven (65.3\%) have had an episode of medication error with 101 (94.4\%) experiencing it between 1 and 5 times. The incident occurred in the afternoon or at night in $73(71.7 \%)$ cases. The commonest type of incident was the administration of wrong drug which occurred on 64 (71.9\%) occasions resulting in 3 deaths. The contributing factors included distraction, tiredness, and overreliance on vial/ampoule colour. Conclusion. Medication errors among Physician-Assistants Anaesthesia are not uncommon leading to harm and even death of patients. The rate of medication errors can be minimised by addressing some of the contributory factors raised by the respondents.

\section{Introduction}

Safety issues in anaesthesia have been discussed informally for some time now and in recent years safety in relation to medicine in general has become topical [1]. Anaesthetists are uniquely placed as specialists who can initiate or influence strategies that may improve the safety and quality of care of patients [2]. One of the key features of patient safety issues is that safety can be improved by learning from incidents and near misses. A number of initiatives have been put in place in recent years, the climax being the signing of "the Helsinki Declaration on Patient Safety in Anaesthesiology" in June 2010 [1]. A number of organisations including the WHO and the World Federation of Societies of Anaesthesiologists have endorsed this document [1].

One of the biggest risks in anaesthetic practice is the administration of drugs most of which are given intravenously. Anaesthetists have the unique responsibility to prescribe and administer potent drugs, usually in rapid sequence [2]. The probability of causing harm or even death of a patient in anaesthetic practice is therefore very high.

Medication errors are common in all areas of clinical practice. The National Coordinating Council for Medication Errors Reporting and Prevention [3] defines a medication error as any preventable event that may cause or lead to inappropriate medication use or patient harm, while the medication is in the control of the healthcare professional, patient, or consumer. The incidence in anaesthesia is estimated to be 1:133 [4]. Medication errors are the second most common category of incidents reported by the National Patient Safety Agency in the United Kingdom [5]. The outcome of these errors ranges from "no harm" to the death of the patient [2]. Common medication errors in anaesthesia include drug swaps or errors in drug dosage especially in children and in relation to opioids and paracetamol [2].

The prevalence of medication errors in anaesthetic practice in Ghana is not known as there are no laid down mechanisms for reporting or tracking down such errors. This 
study was therefore carried out to find the prevalence of medication errors among the Physician-Assistants Anaesthesia (PA A) members who work in various parts of the country. This group was chosen because they provide about $80 \%$ of anaesthesia in the country.

\section{Methodology}

The study was approved by the Committee on Human Research Publication and Ethics, School of Medical Sciences, Kwame Nkrumah University of Science and Technology. A questionnaire was administered to the P-A A who attended the 13th Update in Anaesthesia conference in Kumasi from 16 to 17 April 2013. The questionnaires were collected before the end of the conference.

2.1. Statistical Analysis. IBM SPSS Statistics software version 20 was used in the data analysis. Demographic characteristics of respondents were identified and analysed. Results were summarized as mean and standard deviations for numerical variables, frequencies, and percentages for categorical variables. Chi-square tests of association and Fisher's exact test were performed to study the association between potential risk factors contributing to medication errors, outcome of medication error, period of occurrences, time of the day, and type of medication error. Suggested measures needed for the prevention of medication errors were presented on a frequency table. $p$ values less than 0.05 were considered statistically significant.

\section{Results}

Of the 220 registered participants, 164 (74.6\%) completed the questionnaire. There were a number of questions which were not filled in by the respondents. For example, the sex was indicated by 148 respondents of whom 92 (62.2\%) were males and 56 (37.9) were females. The mean age was 38.3 years (SD 9.4) The details of the hospital type where they practiced, the practice duration, and the number of refresher courses attended in previous years are shown in Table 1.

One hundred and seven (65.2\%) of the respondents had experienced a medication error in their practice out of whom $101(94.4 \%)$ have had it one to five times. Most of the episodes occurred in the afternoon $(42.5 \%)$ or in the night $(26.4 \%)$, the two periods constituting nearly $70 \%$.

When asked about the details of the medication errors, 105 out of 107 answered this section. The administration of the wrong drug was reported by 76 (72.4\%). Even though there was no harm done in 64 of the patients, with minor or moderate harm in nine other patients, there were three deaths. Unfortunately, the name(s) of the wrong drugs were not ascertained. The outcomes of the errors due to wrong dose, wrong dilution, and wrong route are as shown in Table 2. The precise time during the course of the anaesthetic when the error occurred is also shown in Table 2, with most of it $(54.3 \%)$ occurring in the intraoperative period.

Only 92 (86\%) out of the 107 respondents who reported medication error answered the section on the contributing factors. The greatest contributing factor was familiarity with
TABle 1: Demographic characteristics of Physician-Assistants Anaesthesia.

\begin{tabular}{|c|c|c|}
\hline Characteristics & Mean (SD) & $\begin{array}{c}\text { Frequency, } \\
N(\%)\end{array}$ \\
\hline Age & $38.3(9.4)$ & \\
\hline \multicolumn{3}{|l|}{ Sex $^{*}$} \\
\hline Male & & $92(62.2)$ \\
\hline Female & & $56(37.8)$ \\
\hline \multicolumn{3}{|l|}{ Hospital type $^{\dagger}$} \\
\hline Government & & $109(66.5)$ \\
\hline Mission & & $38(23.2)$ \\
\hline Private & & $8(4.9)$ \\
\hline Quasi-government & & $3(1.8)$ \\
\hline \multicolumn{3}{|l|}{ Practice duration $^{\ddagger}$} \\
\hline$<2 \mathrm{yrs}$ & & $32(20.1)$ \\
\hline $2-5$ yrs & & $65(40.9)$ \\
\hline $6-10 \mathrm{yrs}$ & & $29(18.2)$ \\
\hline$>10 \mathrm{yrs}$ & & $33(20.8)$ \\
\hline
\end{tabular}

Number of refresher

courses attended in the past

years $^{\dagger}$

$1-2$

$50(31.6)$

3-4

59 (37.3)

5-6

18 (11.4)

$>6$

31 (19.6)

Total number of participants $=164 ;{ }^{*} 16 \mathrm{did}$ not answer; ${ }^{\dagger} 6 \mathrm{did}$ not answer; ${ }^{\ddagger} 5$ did not answer.

vial/ampoule colour at $37 \%$. This was followed by tiredness (32.6\%) and distraction (19.6\%). There is a statistically significant association between medication error and factors contributing to medication errors $(p$ value $=0.001)$. The other contributing factors as well as the specific type of error are as shown in Table 3. Other contributing factors volunteered by the respondents include lack of vigilance from the respondent, late labelling of drugs, lack of assistance, and the pressure from doing a lot of cases.

Forty-five (43\%) of the errors occurred in the afternoon followed by $33(31 \%)$ in the morning with the night having the least of $27(25 \%)$.

Nonphysician anaesthesia providers run the shift system with the morning shift running from 8 a.m. to 2 p.m., the afternoon shift from 2 p.m. to 8 p.m., and the night shift from 8 p.m. to 8 a.m. The least number of medication errors occurring in the night may be due to the fact that few cases are done during the night.

Regarding the question on the suggested measures to be put in place to prevent medication errors, a number of suggestions were made by the respondents. These can be divided into two main categories: strengthening of the system or structures and improvement in the anaesthetic practice. In the first category were the involvements of anaesthetist in the purchase of anaesthetic drugs, the provision of assistance, and drug labels. In the second category were checking and rechecking of dugs if possible with another person, labelling 
TABLE 2: Nature of medication errors.

\begin{tabular}{|c|c|c|c|c|c|}
\hline & & & lication error, $N$ & & \\
\hline & Wrong drug & Wrong dose & Wrong dilution & Wrong route & Total (\%) \\
\hline Outcome & & & & & \\
\hline No harm & 64 & 13 & 6 & 6 & $89(84.8)$ \\
\hline Minor harm & 6 & 3 & Nil & Nil & $9(8.6)$ \\
\hline Moderate harm & 3 & Nil & Nil & Nil & $3(2.9)$ \\
\hline Severe harm & Nil & 1 & Nil & Nil & $1(1)$ \\
\hline Death & 3 & Nil & Nil & Nil & $3(2.86)$ \\
\hline Total & $76(72.4)$ & $17(16.2)$ & $6(5.7)$ & $6(5.7)$ & $105(100)$ \\
\hline Period of occurre & & & & & \\
\hline Preinduction & 13 & 1 & 1 & 4 & $19(18.1)$ \\
\hline At induction & 15 & 5 & 2 & Nil & $22(20.9)$ \\
\hline Intraoperation & 43 & 10 & 3 & 1 & $57(54.3)$ \\
\hline Postoperation & 4 & 2 & Nil & 1 & $7(6.7)$ \\
\hline Total (\%) & $75(71.4)$ & $18(17.1)$ & $6(5.7)$ & $6(5.7)$ & $105(100)$ \\
\hline
\end{tabular}

${ }^{\S}$ Two did not answer.

TABLE 3: Factors contributing to medication error.

\begin{tabular}{|c|c|c|c|c|c|}
\hline & \multicolumn{5}{|c|}{ Medication error, $N(\%)$} \\
\hline & Wrong drug & Wrong dose & Wrong dilution & Wrong route & Total (\%) \\
\hline \multicolumn{6}{|l|}{ Factors $^{* *}$} \\
\hline Distraction & 10 & 4 & 2 & 2 & $18(19.6)$ \\
\hline Tiredness & 22 & 6 & Nil & 2 & $30(32.6)$ \\
\hline Health & 2 & Nil & Nil & Nil & $2(2.2)$ \\
\hline Poor illumination & 4 & Nil & Nil & Nil & $4(4.4)$ \\
\hline Familiarity with vial/ampoules colour & 29 & 2 & 2 & 1 & $34(37)$ \\
\hline Social problems & 1 & Nil & Nil & Nil & $1(1.1)$ \\
\hline Others $^{\dagger \dagger}$ & 3 & Nil & Nil & Nil & $3(3.3)$ \\
\hline Total (\%) & $71(77.2)$ & $12(13)$ & $4(4.4)$ & $5(5.4)$ & $92(100)$ \\
\hline
\end{tabular}

** 15 did not answer.

${ }^{\dagger \dagger}$ Other contributing factors include lack of vigilance, late labelling of drug, lack of assistance, oxygen administration error, complaints from patient, poor colouration of ampoules, poor labelling of drug, and pressure from doing a lot of cases.

of drugs soon after drawing, and discarding of all drugs unused at the end of the day.

\section{Discussion}

The medication error of $65.2 \%$ reported in this study clearly shows that medication error is not uncommon in Ghana. This figure is however lower than the $85 \%$ reported from Canada [6].

Medication error in anaesthesia has been estimated at 1:133 [4] anaesthetics. The incidence reported from South Africa ranged from 1:250 to $1: 320$ [7]. The incidence from Ghana however cannot be estimated from this study as the total number of anaesthetics given by the respondents was not known.

Medication errors have been reported from other countries $[8,9]$ and from centres including teaching hospitals $[7,9]$. The respondents of this study were all nonphysician anaesthetists in contrast to the study from Nigeria which included physician anaesthetists. About $20 \%$ of the respondents have practiced for less than 2 years. The majority (56\%) however have practiced between 2 and 10 years. In a study from South Africa, experience of the anaesthetist did not influence whether an error occurred or not [7].

The administration of wrong drug was about $72 \%$ of the errors reported in this study. We did not ask about the particular drugs that were involved. All the drugs used in anaesthetic practice have been implicated [10]. Webster and colleagues indicated in their study that $69 \%$ of the errors occurred between different pharmacologic classes [4]. Nwasor and colleagues reported that the common drug swaps included pancuronium instead of suxamethonium and adrenaline instead of atropine [9].

Some of the factors contributing to the administration of wrong drugs were identified in this study. Similarity of the vial/ampoule colour was cited by $37 \%$ of the respondents. Atropine and adrenaline are often presented in $1 \mathrm{~mL}$ amber coloured ampoules in Ghana. The probability of adrenaline 
being given instead of atropine is therefore high if care is not taken.

In Llewellyn et al's study [7], 36.9\% of the errors were due to misidentification of drugs ampoules of which $64.4 \%$ were due to similarly looking ampoules. In the Canadian study, the commonest error was the administration of muscle relaxant instead of reversing agents [6], the commonest contributing factors being syringe swap and misidentification of the syringe labels. The inscriptions on some of these ampoules are hardly visible especially at night. Poor visibility was cited as a factor in the administration of wrong drugs.

Tiredness was the second most important factor contributing to medication error. Some of the hospitals in Ghana have one or two P-A A who do both elective and emergency operations. The highest percentage of operations done in these hospitals is obstetric cases. The relationship between fatigue and medication error has been documented from Australia [11]. In Gordon and colleagues' survey [12], 14.1\% of the errors were due to fatigue. Fatigue alleviation strategies and limitation of only emergency cases after midnight have been suggested.

The wrong dose given to patients could be due to the wrong estimation of the weight of the patients or the wrong dilution of the stock solution such as sodium thiopentone which can be presented as $1 \mathrm{gm}$ vial instead of $0.5 \mathrm{gm}$.

Distraction in the theatre accounted for $19.6 \%$ of the errors. Distraction in theatres is not uncommon, some of which can be considered "legitimate" such as the communication between the anaesthetist and the surgeon. The timing of this "legitimate" distraction can have a serious impact on patient safety. Distraction led to the administration of the wrong drug and the use of wrong route. Other forms of distraction in modern theatres are from cell phones. The pitch of the ringing tone is usually loud and causes a lot of distraction. Cell phones can be put on vibration or silent mode during operations. Unnecessary movements of personnel in and out of the theatres can also cause distraction.

In an editorial by Smith and Mahajan, distraction was implicated in critical incidence development during anaesthesia [13]. Campbell and colleagues [14] observed the entire anaesthetic process, during which 424 distractions were recorded with an overall rate being 0.23 per minute. Their study shows that distractions in theatre are not uncommon and may lead to perioperative critical incidence. Since distractions were cited in this study as a cause of medication error, strategies must be put in place to minimise the risks to patients. Personnel in a particular theatre can mutually agree on when to interrupt a colleague unless of course that interruption is to do with the patient's safety.

Pressure from work overload, the late labelling of drugs, and the lack of assistance in the form of anaesthetic technician were additional factors contributing to medication errors. As indicated earlier, a number of these P-A A are working alone and are under constant pressure from the medical personnel, who are usually the head of the hospital, to do more cases.

Medication errors were recorded throughout the various stages of anaesthesia, from induction to the postoperative period. The highest incidence of $54.3 \%$ occurred during the maintenance of anaesthesia as compared to $21 \%$ at induction.
This is similar to that of Mahajan [10] who reported an incidence of $42 \%$ during maintenance compared to $28 \%$ at induction. The reason could be due to improper labelling of syringes at induction leading to syringe swap or incorrect dilution of the top-up drugs of muscle relaxants or opioids.

Nearly $43 \%$ of the errors occurred in the afternoon as compared to $31 \%$ in the morning. This is not unexpected as fatigue could have set in by the afternoon because the same anaesthetist usually continues till the afternoon. The lowest incidence of $26 \%$ at night could be due to a change in personnel for the night shift.

Anaesthetic practice has progressed from the use of different syringe sizes to indicate the class of drugs to the use of markers to label syringes to the present situation where internationally accepted colour coding for drugs is being used in some countries. However, most hospitals in Ghana use the marker to label syringes. In Gordon and colleagues' study [12], they lamented that South African hospitals have failed to provide internationally accepted colour coded syringes for hospitals.

Colour coding for syringes does not absolve the user for correctly identifying the drug before drawing it. There is still a possibility that a wrong drug will be drawn instead of the intended one and the "correct" label will be put on it. Wildsmith [15] also emphasized the importance of doctors (practitioners) reading the label on the drugs before drawing instead of relying on the colour and shape of ampoules. The same caution was also given by Gordon and his colleagues [12]. Some authors recommend bar code identification of ampoules as additional safety measures using computers that can speak the name of the drug after it has been scanned [16].

Another potential source of danger is the manner in which anaesthetic drugs are stored in theatre. Drugs with completely different actions are packed next to each other [12]. Webster and colleagues have suggested the colour coding of compartments of drug trolleys [17].

The effect of these medication errors on the physiological parameters of the patient depends on the type of drug given. Changes in heart and blood pressure as well as apnoea and paralysis have all been reported [12]. Even though $93 \%$ of the patients in all categories were not harmed or only experienced minor harm, there were three deaths among those patients who received wrong drugs. It is however not possible to indicate the cause(s) of death in these patients. In the Canadian study [6], there were five deaths and three nonfatal cardiac arrest incidents. Of the four anaesthetic related deaths, two were due to overdose of lidocaine and the other two were due to drug swaps, one being the administration of propranolol instead of adrenaline.

Medication errors lead to increased cost of care to the hospital. Studies from the United States give an idea of the cost implication. These medication errors caused one teaching hospital \$5.6 million [18]. The damage to the reputations of both the personnel and the hospital is also another concern [10]. In the rural or semirural settings where most of the P-A A work, news of such nature spreads rapidly throughout the community. Health facilities must put in place measures that will minimise the damage due to such incidents. 


\section{Conclusion}

This study has shown that majority of anaesthesia providers in Ghana who completed this survey reported that they made an error or more in their practice. Even though the majority of the patients did not suffer any harm, the three deaths reported are considered avoidable. The Chinese proverb "the error of one moment becomes the sorrow of a whole [19]" is apt. The long-term complications of the other patients may also not be known to the anaesthetists. All anaesthetists must be aware that this risk exists and must evolve strategies to minimise such risks. A national reporting system is also recommended through the existing physicians and nonphysicians anaesthetic societies through to the Ministry of Health/Ghana Health Service of Ghana.

\section{Competing Interests}

The authors declare that they have no financial or personal relationship which may have inappropriately influenced them in writing this paper.

\section{Acknowledgments}

The authors acknowledge the help of all the P-A A who filled in the questionnaires.

\section{References}

[1] J. Mellin-Olsen, S. Staender, D. K. Whitaker, and A. F. Smith, "The Helsinki declaration on patient safety in anaesthesiology," European Journal of Anaesthesiology, vol. 27, no. 7, pp. 592-597, 2010.

[2] Safe Anaesthesia Liaison Group, "Patient safety update: 1st January 2012 to 31st March 2012 report," Bulletin of the Royal College of Anaesthetists, no. 75, pp. 40-46, 2012.

[3] The National Coordinating Council for Medication Error Reporting and Prevention (NCC MERP), The First Ten Years "Defining the Problem and Developing Solutions", July 2005, http://nccmerp.org/about-medication-errors.

[4] C. S. Webster, A. F. Merry, L. Larsson, K. A. McGrath, and J. Weller, "The frequency and nature of drug administration error during anaesthesia," Anaesthesia and Intensive Care, vol. 29, no. 5, pp. 494-500, 2001.

[5] D. H. Cousins, D. Gerrett, and B. Warner, "A review of medication incidents reported to the National Reporting and Learning System in England and Wales over 6 years (2005-2010)," British Journal of Clinical Pharmacology, vol. 74, no. 4, pp. 597604, 2012.

[6] B. A. Orser, R. J. B. Chen, and D. A. Yee, "Medication errors in anesthetic practice: a survey of 687 practitioners," Canadian Journal of Anaesthesia, vol. 48, no. 2, pp. 139-146, 2001.

[7] R. L. Llewellyn, P. C. Gordon, D. Wheatcroft et al., "Drug administration errors: a prospective survey from three South African teaching hospitals," Anaesthesia and Intensive Care, vol. 37, no. 1, pp. 93-98, 2009.

[8] R. K. Jain and S. Katiyar, "Drug errors in anaesthesiology," Indian Journal of Anaesthesia, vol. 53, no. 5, pp. 539-542, 2009.

[9] E. O. Nwasor, S. T. Sule, and D. B. Mshelia, "Audit of medication errors by anesthetits in North Western Nigeria," Nigerian Journal of Clinical Practice, vol. 17, no. 2, pp. 226-231, 2014.
[10] R. P. Mahajan, "Medication errors: can we prevent them?" British Journal of Anaesthesia, vol. 107, no. 1, pp. 3-5, 2011.

[11] G. P. Morris and R. W. Morris, "An analysis of the first 10 years of the Australian Incident Monitoring study 1987-1997," Anaesthesia and Intensive Care, vol. 28, no. 3, pp. 300-304, 2000.

[12] P. C. Gordon, R. L. Llewellyn, and M. F. M. James, "Drug administration errors by South African anaesthetists-a survey," South African Medical Journal, vol. 96, no. 7, pp. 630-632, 2006.

[13] A. F. Smith and R. P. Mahajan, "National critical incident reporting: improving patient safety," British Journal of Anaesthesia, vol. 103, no. 5, pp. 623-625, 2009.

[14] G. Campbell, K. Arfanis, and A. F. Smith, "Distraction and interruption in anaesthetic practice," British Journal of Anaesthesia, vol. 109, no. 5, pp. 707-715, 2012.

[15] J. A. W. Wildsmith, "Doctors must read drug labels, not whinge about them," The British Medical Journal, vol. 324, no. 7330, article 170, 2002.

[16] C. S. Webster, D. J. Mathew, and A. F. Merry, "Effective labelling is difficult, but safety really does matter," Anaesthesia, vol. 57, no. 2, pp. 201-202, 2002.

[17] C. S. Webster, D. Anderson, and S. Murtagh, "Safety and perioperative medical care," Anaesthesia, vol. 56, no. 5, pp. 496-497, 2001.

[18] D. W. Bates, N. Spell, D. J. Cullen et al., "The costs of adverse drug events in hospitalized patients," The Journal of the American Medical Association, vol. 277, no. 4, pp. 307-311, 1997.

[19] D. Kothari, S. Gupta, C. Sharma, and S. Kothari, "Medication error in anaesthesia and critical care: a cause for concern," Indian Journal of Anaesthesia, vol. 54, no. 3, pp. 187-192, 2010. 


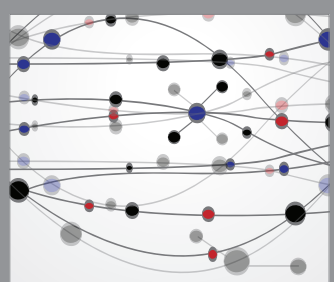

The Scientific World Journal
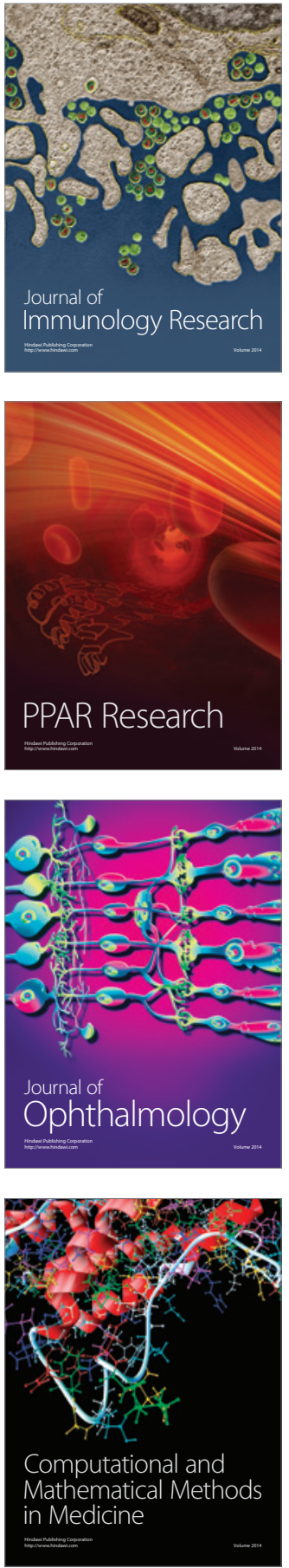

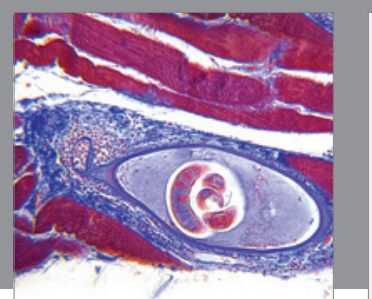

Gastroenterology Research and Practice

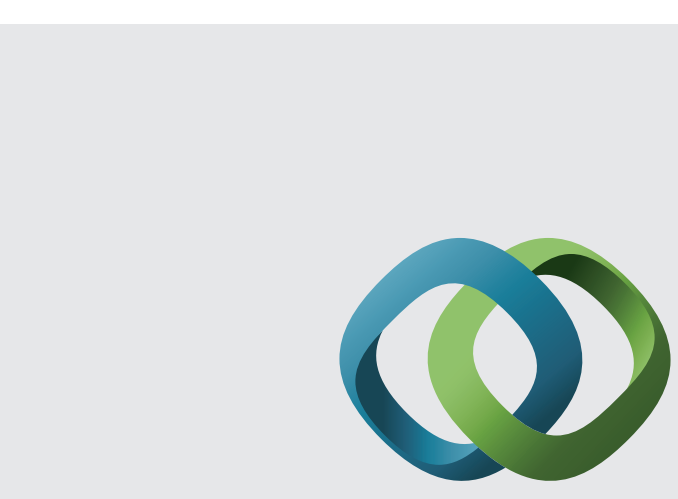

\section{Hindawi}

Submit your manuscripts at

http://www.hindawi.com
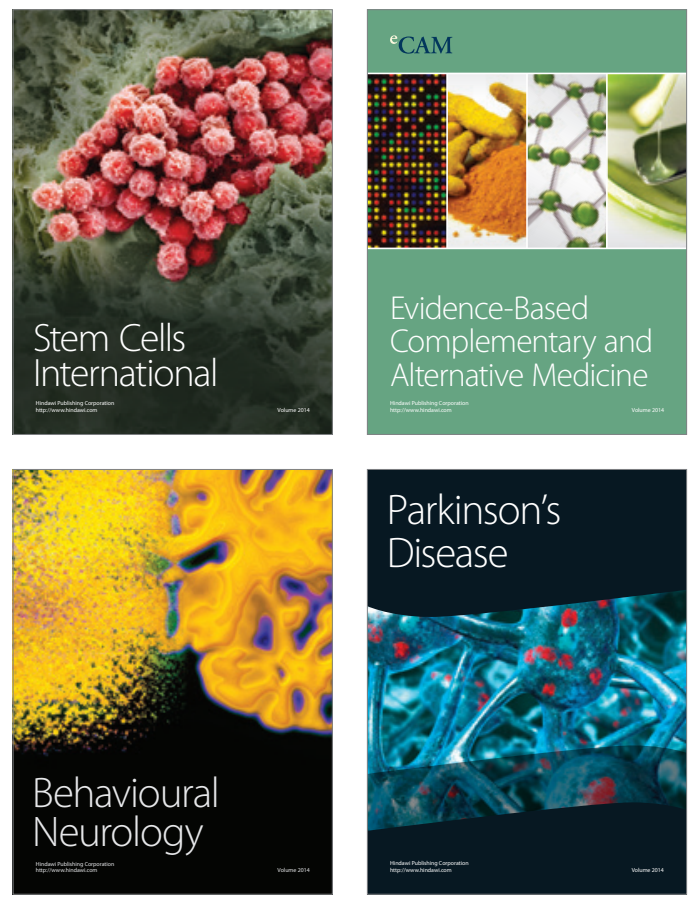
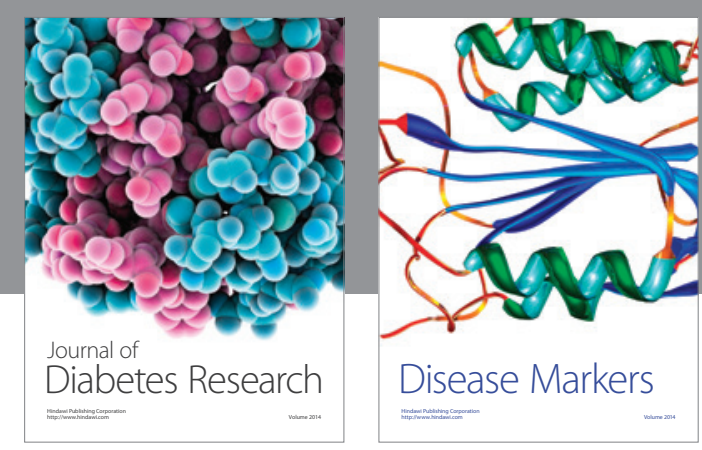

Disease Markers
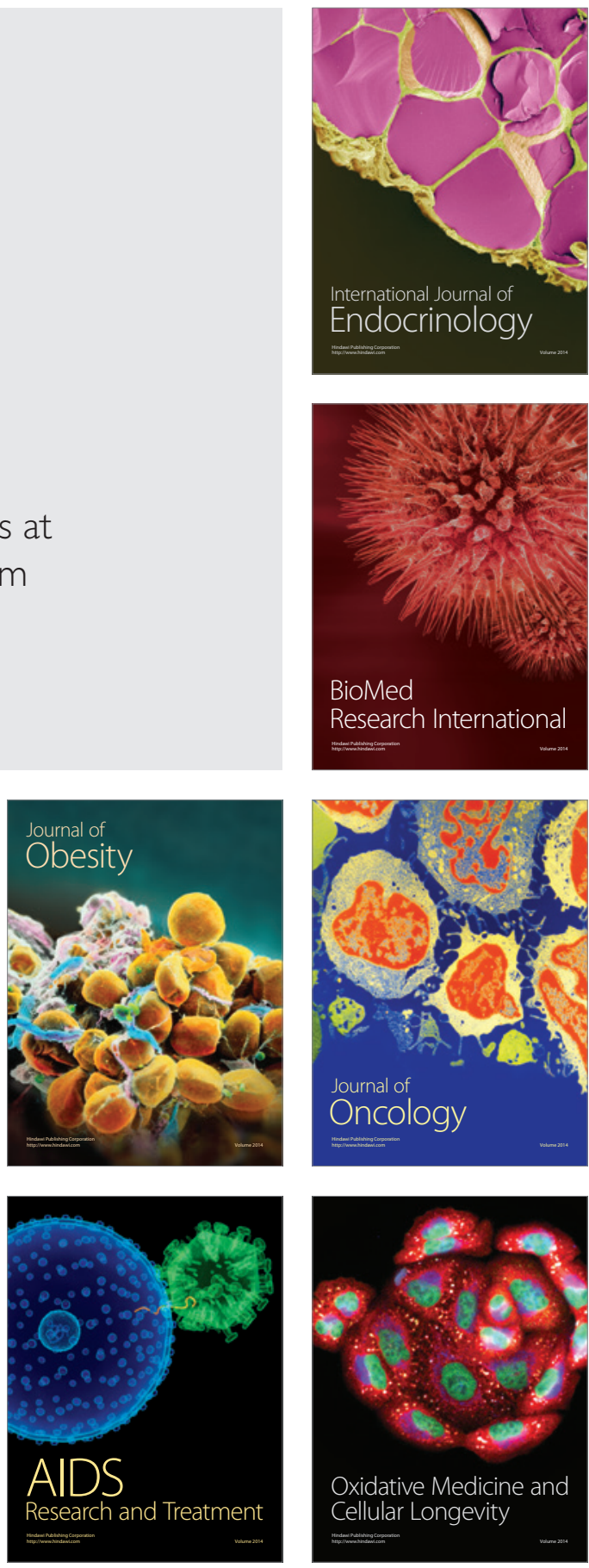